\title{
Notas explicativas do distinctivo
}

\author{
por Paim
}

\section{Razões symbolicas}

\begin{abstract}
A figura central e predominante do distinctivo é o sol, representado por uma aureola de raios dourados que encerra os demais attributos da insignia.

Varias razões nos levaram a essa escolha.

Primeira: ser o sol o symbolo da vida, em analogia com a Medicina que cuida da vida e procura resguarda-la no individuo.
\end{abstract}

Segunda: ser o sól o symbolo da luz, em analogia com a escola que é tradicionalmente considerada o luzeiro das intelligencias, em que os espiritos bebem a luz da sciencia.

Terceira: é de ordem especial, por ser o sól a therapeutica primitiva, que atravéz de todos os tempos prestou á humanidade seus beneficios ineffaveis até os nossos dias em que o sól, symbolo do ar livre é além de medicina efficaz, a base da hygiene.

Quartia: de ordem moral, por ser o sól o astro que vive, para das alturas aquecer e illuminar todos os seres, em analogia com a sciencia, especialmente medica, que deverá humanitariamente, e com elevação zelar pela vida de todos os homens sem distincção de classes, nacionalidades, intelligencia, cultura, moral, etc. cuidando dos grandes problemas sanitarios do mundo.

Quinta: de ordem pedagogica, por ser o sól symbolo do trabalho, que nelle é pontual e perseverante. 
em analogia com a vida do homem da sciencia, que nunca deve furtar-se ao dever de prestar a ella o mais decidido apoio e dar o maximo do seu esforço em pról do progresso scientifico.

Dentro da aureola solar que circumda o distinctivo encontra-se uma faixa verde esmeralda, com o distico: "Faculdade de Medicina de São Paulo».

São trez as razões de ser verde essa tarja:

Primeira: sêr essa côr da esmeralda, pedra symbolica da medicina, adoptada pelos medicos como seu distinctivo.

Segunda: ser ainda a côr dos mares e dos vegetaes duas ricas fontes de vida e de saúde a que a humanidade muito deve. Fica assim representada a medicina domestica, praticada por herbanarios em todos os póvos.

Terceira: por ser ainda o verde o symbolo da esperança que nunca ha-de abandonar o medico no exercicio do seu aposiolado clinico ou de pesquizas, lembrando que a sciencia de todos os tempos registra casos extraordinarios de cura.

Os caracteres do distico são de ouro, symbolizando o desejo que deve existir em todos os estudantes de ver sua escola valiosa pelos seus altos meritos scientificos.

A seguir, contornando o distico pelo lado de dentro, vem a figura da cobra, cujas extremidades envolvem uma taça que se acha pousada na parte inferior do circulo.

A cobra e a taça, encerram trez symbolos:

Primeiro: são symbolos seculares da pharmacia (a taça), filha da chimica e neta da archimia (a serpente), em que os reptis desempenharam papel relevante, de que a therapeutica se serve para a composição dos remedios.

Segundo: por uma analogia moderna a cobra representa ainda a serumtherapia, que cada vez ganha maior terreno na medicina conleporanea. 
Terceiro: representa ainda pela sua natureza selvagem e hostil, o sólo americano, dando a nóta regional e suggerindo o dever que a medicina brasileira tem de vencer os problemas sanitarios nacionaes.

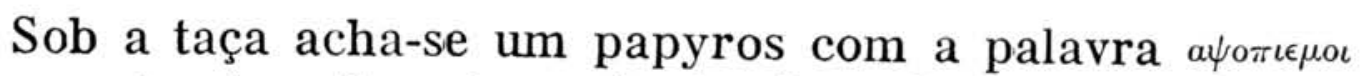
representando não só os "aphorismos" de Hypocrates, como toda a sabedoria medica classica.

A razão de ser branco esse papyros, é symbolisar a clareza de que se deve revestir toda a verdade scientifica, e a pureza e simplicidade de todo o verdadeiro homem de sciencia, restaurando uma tradicional moral scientifica em opposição ao cabotino, ao perfunctorio e ao pedantesco.

A palavra grega $а \psi о \pi \iota \epsilon \mu \iota$ representa o respeito que todo homem de sciencia deve ter pela sabedoria do passado.

Occupa o centro do distinctivo a figura de um templo grego (asclœpia) consagrado á Esculapio, que se desenha em branco sobre fundo verde.

O templo resume-se em quatro columnas e um frontão, pouzadas sobre tres degráus.

A asclœpia symboliza não só a primeira organização da arte medica da antiguidade, como tambem, o monumento da sciencia medica contemporanea. É branco e occupa o centro da figura para melhor exprimir a preponderancia da prophylaxia, para a qual convergem todos os esforços da medicina.

As quatro columnas que sustêm e constituem o templo, representam as quatro épocas culminantes da sciencia medica, com Hypocrates, Galeno, Bichat e Pasteur.

\section{Razões estheticas}

Os leit-motifs da linha esthetica do distinctivo, são: o sol que fornece a disposição geral em circulo dos differentes elementos, e o templo grego, cujo frontão determina o angulo em que foram estylizados todos os pormenores. 
Esses dois rythmos: o circulo e o angulo do frontão do templo, pelo caracter austéro de suas linhas puras e simples, imprimem á insignia um cunho de sobriedade e discreção condizente com a natureza de uma agremiação scientifica.

O circulo inspirado no disco solar acha-se observado na tarja em que se lê o seguinte: "Faculdade de Medicina de S. Paulo", na serpente que coniorna a faixa pelo lado interno e no circulo central em que se acha inscripto o templo.

A palavra $\psi_{\psi}$ do desenho, segue o mesmo movimento.

Essa linha circular, exprime, pela sua identidade com a conformação do planeta e da aboboda celeste, um sentimento de universalidade que se observa em todos os que representam a mesma ideia e que muito bem se harmoniza com o espirito da sciencia.

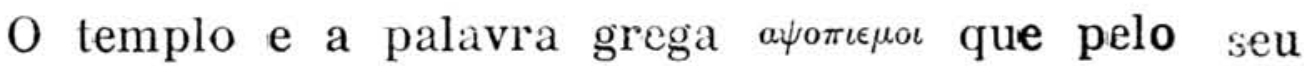
caracter personalissimo não se podem subordinar a nenhum esiylo, inspiraram a linina dos pormenores do desenho.

Primeiro, a terminação dos raios solares em numero de 14, que por ser multiplo de 7, numero cabalistico, fala das praticas sympatinicas e empiricas da medicina do passado, ainda vivas na tradição popular, cujas intenções poderăo vir a ser definidas pela sciencia de algum dia.

O letreiro foi estylisado em ornato grego, afinando com o conjuncto.

A serpente tem em toda a sua extensão um traço em zig-zag, que alem de repetir a cimalha do templo e de consiituir uma primeira ordem de raios solares, combinada com as linhas externas, forma um ornato de estylo indigena brasileiro, o que mais confirma aquella nota nacionalista que a serpente dá. 
A parte inferior da cobra é toda de traços verdes e dourados, convergentes, que repetem o mesmo thema das columnas e dos raios solares.

O templo grego acha-se contido no circulo do meio, que pela disposição do desenho ficou excentrico, permittindo que o ponto central das asclœpia formado pela intercepção das diagonaes do rectangulo em que o teinplo for inscripto, coincida com o centro do desenho. Isso dá a este symbolo um aspecto de solidez e a importancia de cellula mater de que todos os outros se derivam.

Igual impressão dá o cimo do frontão tocar a circunferencia central no ponto em que o eixo do desenho a corta, e as molduras da cimalha terminam naquellas mesma linha.

Para obier-se este resultado foi preciso accomodar as proporções do templo ao espaço, usando prudentemente das liberdades que a heraldica concede.

As columnas, em numero de quatro, se alternam com vãos de igual largura, por maior conveniencia de esthetica.

\section{Informações technicas}

A aureola solar, será de metal amarello, toda cinzelada no sentido dos raios.

Os espaços marcados com verde, serão coloridos com esmalte verde esmeralda, e os marcados com branco serão pintados com esmalte branco.

No circulo central, onde os esmaltes se avisinham, serão separados por ligeiros traços dourados, marcando os contornos e pormenores do templo. 